For the notes of these two cases we are indebted to Dr. W. H. Dickinson, medical registrar to the hospital.

William D-, aged thirty-four, a warehouseman, admitted June 27th. He was quite well and vigorous up to the end of last year. In January he had a violent cold, with cough; this continued, without much interference with his general health, until two months before admission, when his breath became short. This was followed by much loss of flesh, and inability to lie on the left side. He never had any pain in the side, or stitch, and never spat blood. When admitted, the right side of the chest was profoundly dull up to the collar-bone; it visibly bulged, and the intercostal spaces were slightly prominent, contrasting with their condition on the opposite side, where the leanness of the patient showed deep furrows between the ribs. The heart pulsated very visibly about two inches below the left nipple and just ontside it. The cardiac sounds were distinctly audible all over the right side; they were as loud at the right nipple as they usually are in the precordial region, while at the left the sounds were exaggerated. Respiration, when tranquil, could be heard as low as the angle of the right scapula; while, when deeply drawn, it conld be faintly distin guished down to the bottom of the lung. The man was much emaciated, and the features were sharp, but the complexion was not peculiar. He usually lay on his back, inclined towards the right side. The breathing was not much embarrassed, 22 per minute; pulse 120. The tongue was furred, but otherwise natural. Urine lithatic, but not albuminous. He had ordinary diet and porter. Paracentesis was at once ordered, but delayed by the surgical officials; and a tonic medicine was prescribed. From the 4th of July he grew worse day by day, and com plained of depression and sinking. He often lay half back in oed, resting on his two elbows. He could not sleep. The pulse was now full and jerking, but very feeble, and he coughed up much matter, like dark mucus. On the 5th, six ounces of wine were prescribed. A puncture was made on the $6 \mathrm{th}$, and about three ounces of thick sanious pus withdrawn by means of cupping-glasses. No sensible relief was produced. He became weak and faint, and the features were sunken. Another attempt was made on the 9 th $\mathrm{July}$ to relieve him by means of a small puncture; no evacuation took place at the time, but about half a pint of pus escaped during the night. He became faint as the discharge went on; it continued to dribble all day, and at night he became completely swamped. He complained of nausea and faintness, and, although stimulants were freely given, he sank, apparently by asthenia, on the following morning.

Autopsy, thirty-five hours after death. - Body somewhat emaciated; abdomen tympanitic. An empty sac of an inguinal hernia was found on the left side. - Thorax : There was a small opening far back, on the right side of the thorax, through which, with some trouble, a probe was passed into the pleural cavity; pus was exuding from this wound. The posterior mediastinum contained a large malignant tumour, of the hard, encephaloid variety; it filled all the space between the rreat vessels and the lung, and had attacked the latter. The whole tissue of the lung was perfectly disorganized, and presented a texture riddled with abscesses. This texture seemed to consist principally of the remains of bronchial tubes and vessels. There were no traces of malignant disease in it. The whole lung seemed perfectly useless as a breathing organ. The upper three-fourths of the right pleura seemed tolerably healthy in structure. It was distended by a very large quantity (more than a pint) of creamy pus. There were two openings into this cavity, towards its lower part. One, which seemed to have been made with the knife or trocar, was situated close to the upper border of the fifth rib. The other, larger and more irregular, was situated at the next lower intercostal space. They both communicated, though indirectly, with the exterual wound The lower fourth of the pleura was adherent and implicated, with the base of the lung and diaphragm, in a mass of malignant disease. The left pleura was healthy (with the exception of a few adhesions), as were the corresponding lung and the heart. In the arch of the aorta were a few loose glands infiltrated with malignant disease. The muscles around the wound were thickened, and two or three small abscesses existed there.-Abdomen : A great part of the diaphragm was so infiltrated by the malignant disease that none of it natural tissue could be distinguished. The malignant mass reached down the spine, lying in front of the lumbar vertebræ, nearly as low as the sacro-vertebral angle. It was lobulated on its surface, and had much the appearance of a mass of dis eased glands. The aorta and vena cava passed behind it, but none of the large vessels seemed compressed. The liver was large and soft; its anterior edge contained a single tubercle of malignant disease, about as large as a hazel-nut. The spleen was large, but healthy. The kidneys were large, and coarse in texture.

\section{GUY'S HOSPITAL.}

SEQUEL TO A CASE OF RMPTEMA, IN WHICH THORACENTESIS WAS PERFORMED, AND A DRAINAGE TUBE WORN.

(Under the care of Dr. GuLx.)

THE particulars of the following case appeared in our "Mirror" (vol. ii. 1859, p. 482); and we then stated that the chest was slowly refilling, and probably a third operation of thoracentesis would be required. The patient had been labouring under the effects of pleuritis eight weeks before admission, and died after being in the hospital about thee months. The third tapping was not performed; but the details of the autopsy show that the pus was on the point of bursting through the thoracic walls, and had infiltrated the neighbouring tissues as far as the abdominal muscles:-

Henry T_- aged seventeen, admitted on Sept. 7th, 1859, for empyema; tapped, and drainage pipe inserted. He died on Dec. 5th. During the last two or three weeks the fluid again collected, so that the right side of the chest was universally dull on percussion.

Autopsy. - Body much wasted. The right side of the chest was completely filled with pus, amounting to several pints. This was good pus, and not foetid. The matter had been endeavouring to escape externally, for not only had it softened the scar made by the troear, and was oozing through the wound, but in several places around had softened the intercostal muscles, so that when the integument was reflected purulent matter was found infiltrating the cellular tissue, and had reached as low as the abdominal muscles. The right lung was compressed into a very small space against the spine, and carnified. The tissue was healthy. A careful examination of the surface, on removal of the layers of lymph, failed to discover any opening in the lung through which any matter could have readily passed. All the other organs were perfectly healthy.

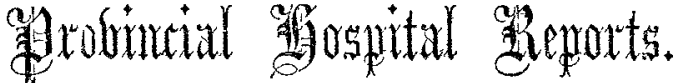

\section{NORTHAMPTON INFIRMARY}

DEATH FROM CHLOROFORM.

(Communicated by J. Foster Gray, Esq., F.R.C.S.)

P. C- aged forty-two years, a tall, stout, muscular Irishman, was admitted, under the care of Mr. Mash, Sept. Ist, 1860. He was the subject of a lipoma, about the size of a closed hand, seated in the middle line between the upper border of the scapulæ. On September 5th he was taken into the operating room for the purpose of having this removed. As the operation was considered neither dangerous nor very painful, he was strongly dissuaded by his surgeon from taking chloroform; but he, nevertheless, expressed an urgent desire that it should be administered. After consultation with $\mathbf{M r}$. Ashdown, as there seemed on auscultation to be no special contra-indicating circumstances, his wish was acceded to, and the chloroform was accordingly given by Mr. Gray, the housesurgeon. It was administered on a single fold of thin lint, and after three or four minutes' inhalation the patient became ex. cited and delirious, struggled a good deal, and talked inces. santly. In the course of about eight minutes more these symptoms subsided, the face became much congested, and the breathing stertorous. At this time the pulse was full and re gular, and the orbicular acted distinctly though rather sluggishly. The administration of chloroform was then wholly suspended, and the patient, being deemed in a fitting state for operation, was turned over on the left side in order to expose the tumour. This position being found inconvenient, a further change was required to adapt the head and shoulders on pillows, so as to expose the tumour effectually, and in the process of effecting this, respiration was observed suddenly to cease. The tongue was immediately drawn forward by artery forceps, cold water freely dashed over the face and chest, and artificial 